\title{
The evolution of rectal and urinary toxicity and immune response in prostate cancer patients treated with two three-dimensional conformal radiotherapy techniques
}

Jana Vranova ${ }^{1,4}$, Stepan Vinakurau ${ }^{2}$, Jan Richter ${ }^{3}$, Miroslav Starec ${ }^{1}$, Anna Fiserova ${ }^{3^{*}}$ and Jozef Rosina $a^{4,1}$

\begin{abstract}
Background: Our research compared whole pelvic (WP) and prostate-only (PO) 3-dimensional conformal radiotherapy (3DCRT) techniques in terms of the incidence and evolution of acute and late toxicity of the rectum and urinary bladder, and identified the PTV-parameters influencing these damages and changes in antitumor immune response.
\end{abstract}

Methods: We analyzed 197 prostate cancer patients undergoing 3DCRT for gastrointestinal (GI) and genitourinary (GU) toxicities, and conducted a pilot immunological study including flow cytometry and an NK cell cytotoxicity assay. Acute and late toxicities were recorded according to the RTOG and the LENT-SOMA scales, respectively. Univariate and multivariate analyses were conducted for factors associated with toxicity.

Results: In the WP group, an increase of acute rectal toxicity was observed. A higher incidence of late GI/GU toxicity appeared in the PO group. Only 18 patients (WP-7.76\% and PO-11.11\%) suffered severe late GI toxicity, and 26 patients (WP-11.21\% and PO-16.05\%) severe late GU toxicity. In the majority of acute toxicity suffering patients, the diminution of late $\mathrm{Gl} / \mathrm{GU}$ toxicity to grade 1 or to no toxicity after radiotherapy was observed. The 3DCRT technique itself, patient age, T stage of TNM classification, surgical intervention, and some dose-volume parameters emerged as important factors in the probability of developing acute and late GI/GU toxicity. The proportion and differentiation of NK cells positively correlated during 3DCRT and negatively so after its completion with dosevolumes of the rectum and urinary bladder. T and NKT cells were down-regulated throughout the whole period. We found a negative correlation between leukocyte numbers and bone marrow irradiated by 44-54 Gy and a positive one for NK cell proportion and doses of 5-25 Gy. The acute GU, late GU, and Gl toxicities up-regulated the T cell (CTL) numbers and NK cytotoxicity.

Conclusion: Our study demonstrates the association of acute and late damage of the urinary bladder and rectum, with clinical and treatment related factors. The 3DCRT itself does not induce the late Gl or GU toxicity and rather reduces the risk of transition from acute to late toxicity. We have described for the first time the correlation between organs at risk, dose-volume parameters, and the immunological profile.

Keywords: 3-dimensional conformal radiotherapy (3DCRT), gastrointestinal and genitourinary toxicity, prostate cancer, NK cells, PTV parameters, pelvic bone marrow

\footnotetext{
*Correspondence: fiserova@biomed.cas.cz

${ }^{3}$ Department of Immunology and Gnotobiology, Institute of Microbiology, Academy of Sciences of the Czech Republic, v.v.i., Prague, Czech Republic Full list of author information is available at the end of the article
} 


\section{Background}

Quality of life is becoming one of the most significant issues in treatment decision-making, in general, and more so in prostate cancer [1]. Thus late rectal and urinary damage became a major concern in prostate cancer; and many studies have been dedicated to the search for correlations between dose-volume, treatmentrelated factors, and late GI and GU toxicities [2-7]. Three-dimensional conformal radiotherapy (3DCRT) represents one of the standard treatments of prostate cancer allowing the delivery of highly "conformed" (focused) radiation to the cancer cells, while significantly reducing the amount of radiation received by surrounding healthy tissue. 3DCRT should increase the rate of tumor control, while also decreasing side effects. In spite of this focus, a higher dose to the prostate implies that the surrounding organs at risk (OARs) may also receive higher doses.

In addition, local radiation therapy (RT) alters the balance of circulating immune cells by the depletion of radiosensitive cell subsets [8]. Recently, radiation-induced functional changes in immune cells raised interest, suggesting the possible use of radiation as an antitumor immune response enhancer. Irradiation can induce leukopenia due to apoptosis of various leukocyte subpopulations. The acute exposure to low- and high-dose irradiation in mouse models changes the quantitative and functional parameters of immune cells, due to different sensitivity of splenocyte subsets to radiation doses [9]. Similar effect was described in vitro for cervical cancer patients [10]. Tabi et al. reported a prevalent loss of naive and early memory cells vs. more differentiated T cells in peripheral blood of patients during RT to the pelvis [11]. The release of the heat shock protein 72 (HSP72) during RT increased the cytotoxic CTL and NK cells [12]. Some pathological changes can be caused by the apoptosis of bone marrow (BM) stem cells and BM stromal damage [13]. Radiation-induced BM injury depends on both the radiation dose and the volume of BM irradiated [14].

We performed a prospective 4-year study, enrolling prostate cancer patients to elucidate whether the risk level of acute and particularly late rectal and urinary toxicities caused by 3DCRT techniques (whole pelvic (WP) and prostate-only (PO)), are at an acceptable level. This study reports our 42-month follow-up results, and evaluates the relationships between pretreatment, acute and late rectal and urinary syndromes and tumor-, patient- and treatment-related factors. In the last 3 years of the study, we investigated the influence of 3DCRT techniques, as well as the GI and GU toxicity on selected patient immune parameters, with special regard to the cells involved in antitumor immunity (natural killer-NK, NKT, and T).

\section{Methods}

\section{Patients and clinical protocol}

Data for the study were collected from 245 consecutive patients with Stage T1 to T3 clinically localized prostate adenocarcinoma, treated with 3DCRT (2004-2009) at the Department of Radiotherapy and Oncology, Motol University Hospital, Prague, Czech Republic. 48 patients with follow-up shorter than 24 months were excluded from the study. The study population thus consisted of 197 patients. Patients according to their health and lymph nodal status (classified by Prostate cancer staging nomograms-Partin tables) [15] were divided into two groups: those who underwent whole pelvic (WP) radiotherapy-irradiation of prostate, seminal vesicles, and lymph nodes followed by a prostate boost (116 patients, $59 \%$ ); and prostate-only (PO) radiotherapy-irradiation of prostate and seminal vesicles (81 patients, $41 \%$ ). Followup evaluations after treatment were performed at 3 to 6 month intervals. The median follow-up was 42 months, ranging from 24 to 55 months. Main patient characteristics and main disorders are summarized in Table 1.

Acute and late GI and GU toxicities were studied in order to identify the treatment-related, clinical and patient characteristics that correlated with the severity of complications and disorders. Acute reactions included those arising during treatment or within 90 days after RT completion. Late complications were defined as those developing more than 90 days after the last treatment. Acute and late toxicities were scored according to RTOG and LENT-SOMA morbidity scale (grades 1-5). Into the category of low toxicities were encompassed the patients without the need of pharmacological intervention (grade 1 ), while the serious toxicity (grade $\geq 2$ ) was under medication. In 37 cases (WP: $n=16$; PO: $n$ $=21$ ) the immune response before treatment, during 3DCRT (day 14), and 15-20 days after treatment completion was evaluated. The protocol was approved by the local board ethics committee; and written informed consent was obtained from all patients.

\section{Irradiation technique, target volume and critical normal structure definition}

Treatment planning and irradiation were performed with the patients in supine position (using knee and ankle supports) with an emptied rectum and "comfortably full” bladder filling. 3D conformal treatment planning based on CT images with $5 \mathrm{~mm}$ thickness, involved delineation of CTVs, PTVs and organs at risk, according to ICRU 50 and 62 recommendations. The plans, using MLC to shape beams, were calculated on Eclipse treatment planning system. Box technique or four wedged field technique (two lateral and two oblique fields at angles of $90^{\circ}, 270^{\circ}, 30^{\circ}$ and $330^{\circ}$ ) was used. The 
Table 1 Patient characteristics

\begin{tabular}{|c|c|c|}
\hline Characteristics & WP $(n=116)$ & $\mathrm{PO}(\mathrm{n}=81)$ \\
\hline \multicolumn{3}{|l|}{ Age } \\
\hline Median & 73 & 74 \\
\hline Range & $57-100$ & $57-92$ \\
\hline Mean \pm SD & $72.93 \pm 8.55$ & $74.88 \pm 7.79$ \\
\hline \multicolumn{3}{|l|}{ TNM Stage } \\
\hline TO & $1(0.86 \%)$ & - \\
\hline $\mathrm{T} 1$ & $6(5.17 \%)$ & $22(27.16 \%)$ \\
\hline $\mathrm{T} 2$ & 34 (29.31\%) & $30(37.04 \%)$ \\
\hline $\mathrm{T} 3$ & $62(53.44 \%)$ & $15(18.52 \%)$ \\
\hline $\mathrm{T} 4$ & $4(3.45 \%)$ & $1(1.24 \%)$ \\
\hline Metastases & $2(1.72 \%)$ & - \\
\hline \multicolumn{3}{|l|}{ Gleason score } \\
\hline Median & 7 & 5 \\
\hline Range & $2-9$ & $3-10$ \\
\hline \multicolumn{3}{|l|}{ Initial PSA [ng/mL] } \\
\hline Median & 19 & 10 \\
\hline Range & $2-133$ & $1-97$ \\
\hline Mean \pm SD & $31.00 \pm 8.67$ & $12.46 \pm 2.34$ \\
\hline ADT & 93 (80.07\%) & $33(40.74 \%)$ \\
\hline \multicolumn{3}{|l|}{ Previous surgery } \\
\hline $\mathrm{RP}$ & $23(19.83 \%)$ & $22(27.16 \%)$ \\
\hline TURP & 7 (6.03\%) & $5(6.17 \%)$ \\
\hline \multicolumn{3}{|l|}{ Therapy duration (m) } \\
\hline Median & 57 & 54 \\
\hline Range & $33-81$ & $22-80$ \\
\hline Mean \pm SD & $57.50 \pm 5.56$ & $54.04 \pm 7.03$ \\
\hline \multicolumn{3}{|l|}{ Recurrence Risk* } \\
\hline Low & $1(0.86 \%)$ & $19(23.46 \%)$ \\
\hline Intermediate & $20(17.24 \%)$ & $38(46.91 \%)$ \\
\hline High & $94(81.03 \%)$ & $23(28.40 \%)$ \\
\hline \multicolumn{3}{|l|}{ Prescription dose (Gy) } \\
\hline$\leq 71$ & $60(51.72 \%)$ & $6(7.41 \%)$ \\
\hline 72,73 & 53 (45.69\%) & 72 (88.89\%) \\
\hline$\geq 74$ & $3(2.59 \%)$ & $3(3.70 \%)$ \\
\hline \multicolumn{3}{|l|}{ Disorders } \\
\hline Without complications & 49 (42.24\%) & $37(45.86 \%)$ \\
\hline Cystoureteritis & 16 (13.79\%) & $15(18.52 \%)$ \\
\hline Cystoureteritis + diarrhea & 15 (12.93\%) & $1(1.23 \%)$ \\
\hline Proctocolitis + diarrhea & $28(24.14 \%)$ & $14(17.28 \%)$ \\
\hline Unknown & 8 (6.69\%) & 14 (17.28\%) \\
\hline
\end{tabular}

*Recurrence risk was determined according to Canadian Consensus (Lukka 2002): low risk (T1-2a, Gleason $\leq 6, P S A<10 \mathrm{ng} / \mathrm{mL}$ ), intermediate risk (T2b$2 \mathrm{c}$, Gleason = 7, PSA $10-20 \mathrm{ng} / \mathrm{mL})$, high risk (T3-4, Gleason $\geq 8$, PSA $>20 \mathrm{ng} /$ $\mathrm{mL})$

dose was normalized to the ICRU reference point, located in the central part of the PTV or near the central axis of the beam intersection, according to ICRU 50. Dose homogeneity was between $95 \%$ and $107 \%$ of the ICRU reference dose. Dose-volume histograms were used for evaluation of doses to target volumes and organs at risk. DRRs were generated for all treatment beams and for two extra setup beams from the anteroposterior (AP) and the lateral directions (LAT).

Before the radiotherapy, the treatment plans were simulated on a conventional simulator (Ximatron and Acuity $^{\circledR}$, Varian Medical Systems). The isocenter was marked on the patient's skin. Patients were irradiated on a Clinac 2100 C/D (Varian) equipped with Millenium MLC-120 with beams of $18 \mathrm{MV}$ or $6 \mathrm{MV}$. The dose was delivered in daily fractions of 1.8 Gy to the pelvis and of 2 Gy to the prostate and seminal vesicles, in given period five sessions per week. In the treatment room, the patients were aligned on a carbon-fiber couch panel within their immobilization device using the skin marks. Before the therapy, patient set-up was checked using electronic portal imaging (PortalVision PV-aS500 ${ }^{\circledR}$ ). Simulator images of setup fields were used as reference images for matching with portal images. Planning target volume (PTV) of the prostate (PTV3) was the entire organ (clinical target volume of prostate-CTV3), and PTV2 was the entire prostate and seminal vesicles (CTV2). Both PTVs were enlarged by $1.5 \mathrm{~cm}$ margin, except for the prostate-rectum interface where a $1 \mathrm{~cm}$ margin was again used to decrease the risk of rectal toxicity. PTV1 in the WP Group was only the CTV of lymph nodes (LNs). LNs were defined according to RTOG recommendations (treatment of only subaortic presacral LNs, contours of common iliac vessels starting at the L5/S1 interspace, external iliac contours stopping at the top of femoral heads, and contours of obturator LNs stopping at the top of the symphysis pubis) plus a $1 \mathrm{~cm}$ margin.

Patients from the PO group received a dose of $60 \mathrm{~Gy}$ in 30 fractions to the PTV2. Then the PTV3 received the prescribed dose of 10-18 Gy in 5-9 fractions. Patients from the WP group received a dose of $45 \mathrm{~Gy}$ in 25 fractions to the PTV1, then a dose of 20 Gy in 10 fractions to the PTV2. Finally the PTV3 received the prescribed dose 6-10 Gy in 3-5 fractions. Dose volume histograms (DVH) were generated for all PTVs and OARs. The OARs included the bladder, rectum, bone marrow, and femoral head.

\section{Pelvic bone marrow definition}

For each patient, the pelvic bone marrow (PBM) volume was first defined according to the method described by Mell et al. [16]. The external contour of the PBM was delineated on the planning $\mathrm{CT}$ using bone windows. Three sub sites were defined: 1) iliac BM (IBM), extending from the iliac crests to the superior border of the femoral head; 2) lower pelvis (LP), consisting of the pubes, ischia, acetabula, and proximal femora, extending from the superior border of the femoral heads to the inferior border of the ischial tuberosities; and 3) lumbosacral spine (LS), extending from the superior border of 
the L5 vertebral body to the coccyx, but not extending below the superior border of the femoral head. To find the association of local radiation doses and changes in the number of leukocytes among patients with different body sizes, the percentage of BM irradiated volume at different doses was used as a first approximation.

\section{Cell separation for immunological evaluations}

Citrated blood samples from patients were separated by Ficoll-Hypaque 1,077 (Sigma-Aldrich, St. Louis, MO, USA) density centrifugation for $40 \mathrm{~min}$ to obtain the peripheral blood mononuclear cell (PBMC) fraction.

\section{Flow cytometry}

The fluorochrome-conjugated antibodies CD3-Pacific Blue (UCHT1), CD4-APC-Alexa Fluor 750 (S3.5), CD8Pacific Orange (3B5) CD19-Pacific Blue (HD37), CD20PE-Cy7 (2H7), CD38-PerCP-Cy5.5 (HIT2), and CD56APC (MEM-188), were obtained from Dako (Glostrup, Denmark), Exbio (Prague, Czech Republic), BD Biosciences (Franklin Lakes, NJ, USA), and e-Bioscience (San Diego, CA, USA). PBMCs $\left(5 \times 10^{5}\right.$ cells/well $)$ were stained with the antibody mixture for $30 \mathrm{~min}$ on ice, washed, and measured with a Becton Dickinson LSRII instrument (BD Biosciences). We included single-stain controls for further offline compensation. Measurement and subsequent analysis was performed using FACSDiva (BD Biosciences) and TreeStar FlowJo 8 (Ashland, OR, USA) software, respectively.

\section{NK cell-mediated cytotoxicity}

The standard ${ }^{51} \mathrm{Cr}$-release assay was performed with PBMCs from patients as effectors and the NK cell-sensitive K562 erythroleukemia cell line as targets. PBMC $\left(1.6 \times 10^{5}\right.$ cells/well $)$ were incubated with $10^{4}$ $\mathrm{Na}_{2}{ }^{51} \mathrm{CrO}_{4}$-labeled target cells in round-bottomed 96 well microtitre plates (NUNC) at $37^{\circ} \mathrm{C}$, in a humidified atmosphere containing $5 \% \mathrm{CO}_{2}$. NK cell activity was evaluated after $4 \mathrm{hr}$ of incubation, and calculated as described previously [17].

\section{Statistical analysis}

We investigated all GI and GU toxicities (late and acute) separately. There were only 3 cases of grade 3 acute GI toxicity, only 5 cases of grade 3 acute GU toxicity, and none of grade 4 or 5 . Similar observation was made for late GI toxicity (only 5 cases of grade 3, 1 of grade 4, and no instances of grade 5) and for late GU toxicity (only 13 patients of grade 3 and none of grade 4 or 5). As a consequence, we grouped the toxicity levels of all diagnosed toxicities (acute GI, acute GU, late GI, and late GU) in two categories and analyzed the binary response. The grouping of responses considered was: high toxicity (grade 2-3) vs. low or no toxicity (grades 1 or 0 ).
The grouped data were analyzed using multivariate logistic regression models. The list of predictive factors was the same for acute and late toxicities; except for the addition of acute toxicity, as the next predictive factor of late OAR damage. The patient-, tumor-, and treatment-related factors were as follows: 3DCRT technique used (WP vs. PO); volumes of rectum and urinary bladder; minimum, maximum, and mean dose received by the rectum and urinary bladder $\left(D_{\text {min }}, D_{\text {max }}, D_{\text {mean }}\right)$; percentage of rectum and urinary bladder volume receiving $40 \mathrm{~Gy}, 50 \mathrm{~Gy}, 60 \mathrm{~Gy}$, and $70 \mathrm{~Gy}$, respectively; patient age; stage T of TNM classification; initial PSA; Gleason score; androgen deprivation therapy (ADT) added to RT (yes/no); surgical intervention (None/ Transurethral resection/Radical prostatectomy) of the prostate (NONE/TURP/RP); occurrence of hemorrhoids (yes/no); and duration of RT (weeks). A Pearson's $\chi^{2}$ test or, in the case of small sample size, Fisher's exact test was used to examine whether there was a statistically significant difference in the occurrence and evolution of acute and particularly late GU and GI toxicity between the two observed 3DCRT techniques.

To evaluate the association of immune response and toxicity level, the patients were divided in the group $\mathrm{T}$ (patients with any toxicity level-grades 1-3) and group 0, those with no toxicity (grade 0 ). To compare the immune parameters between these groups of patients the $t$-test was performed. To find the relationship between immune response in prostate cancer patients and treatment related factors, Pearson's correlation coefficients were calculated.

For statistical analysis Statsoft's STATISTICA version 9 and SPSS Statistics version 18 were used. All tests were considered to be statistically significant at the level of $\mathrm{p}<0.05$. The required sample size for all performed statistical tests was calculated using IBM SPSS SamplePower software version 3 .

\section{Results}

Logistic regression models for $\mathrm{Gl}$ and $\mathrm{GU}$ toxicities

Four logistic regression models for acute GI, acute GU, late GI, and late GU toxicity were created. All models were statistically significant and adequately interpolated the data; however in both models for late toxicities, GI and GU, a large disparity between the number of patients in groups with high toxicity vs. low or no toxicity was observed. The classification ability of all four models was very good-80.0\% for acute GI toxicity, 78.9\% for acute GU toxicity, $76.3 \%$ for late GI toxicity, and $76.0 \%$ for late GU toxicity. The area under the ROC curve (AUC) which determines the discrimination power of the logistic model reached the following values: 0.836 for acute GI toxicity-discrimination quality according to Tape [18], "Good"; 0.810 for acute GU 
toxicity-"Good"; 0.784 for late GI-"Fair"; and 0.761 for late GU toxicity-"Fair".

The significance level and odds ratio for statistically significant regression coefficients are summarized in Table 2 for acute and late GI and GU toxicity. Acute GI and GU toxicities were significantly dependent on patients' increasing age, and the chance of developing high toxicity levels greaten. For late GI and GU toxicities, the larger irradiated volume of OARs (rectum and urinary bladder) enhanced the chance of high-level toxicity occurrence. Other important predictors of acute GI toxicity were the percentage of rectum volume receiving $70 \mathrm{~Gy}$ (the higher the percentage of rectum, the higher the chance of high level toxicity) and the 3DCRT technique used, where the high-level toxicity developed when the WP technique was used (26.16 times greater than in the case of the PO technique). The higher $\mathrm{T}$ stage of TNM classification and the acute GI toxicity significantly increased the probability of late GI toxicity occurrence. The results pointed to the significant association of acute $\mathrm{GU}$ toxicity and the percentage of the urinary bladder receiving $50 \mathrm{~Gy}$, and the association of late GU toxicity with the percentage of the urinary bladder receiving $40 \mathrm{~Gy}$. Both types of urinary toxicities (acute and late) were augmented by radical prostatectomy prior to radiotherapy (NONE vs. RP) that increased the occurrence of high-level toxicity for acute and late GU toxicity 7.35 times $(\mathrm{OR}=0.136)$ and 11.15 times $(\mathrm{OR}=0.090)$, respectively. Another important statistically significant predictor found for late GU toxicity was the PO type of 3DCRT that evoked the development of high-level toxicity 1.72 times more $(\mathrm{OR}=0.580)$ in comparison with WP technique.

\section{GI and GU toxicity evolution after WP and PO 3DCRT techniques}

The used 3DCRT technique was proven as an important factor influencing the development of GI and GU toxicity. Consequently, we analyzed the occurrence and evolution of late GI and GU toxicity from pretreatment symptoms through acute GI and GU toxicity in each group of patients separately. The proportion of patients suffering pretreatment GU, as well as GI pathologies, was comparable in the groups undergoing either the WP or PO 3DCRT therapy. The proportion of GU toxicity did not change significantly between the WP and $\mathrm{PO}$ techniques in all appearing grades (0-3). The results of toxicity dynamics are summarized in Table 3 . The values of the last late GI and GU toxicity observed in patients during their last inspection are shown.

In the cohort of patients included in the WP group, pretreatment GI toxicity of grade 2 was found in the history of 2 patients (1.72\%), and only 1 patient $(0.86 \%)$ showed grade 3. During treatment or within the first 90 days after treatment, acute grade 2 GI toxicity occurred in $65(56.03 \%)$ and grade 3 GI toxicity in 3 patients (2.59\%). The severe late GI toxicity of grade 2 occurred in $5(4.31 \%)$, grade 3 in 3 patients $(2.59 \%)$, and grade 4 in 1 patient $(0.86 \%)$. There were no late grade $5 \mathrm{GI}$ toxicity-suffering patients in this group. Pretreatment GU damage of grade 2 was found in the history of 4 patients (3.44\%) and grade 3 in the history of 2 patients (1.72\%). WP 3DCRT evoked acute grade 2 GU toxicity in 30 (37.04\%) and acute grade $3 \mathrm{GU}$ toxicity in 4 patients (3.45\%). Severe late GU toxicity of grade 2 occurred in 8 patients $(5.76 \%)$ and grade 3 in 6 patients $(7.41 \%)$. There were no late grade 4 or $5 \mathrm{GU}$ toxicities observed.

Table 2 Logistic regression models for acute and late GI and GU toxicities.

\begin{tabular}{|c|c|c|c|c|c|c|c|}
\hline \multicolumn{5}{|c|}{ Acute GI toxicity } & \multicolumn{3}{|c|}{ Late GI toxicity } \\
\hline Variable & OR & $95 \% \mathrm{Cl}$ & $\mathbf{p}$ & Variable & OR & $95 \% \mathrm{Cl}$ & $\mathbf{p}$ \\
\hline Age & 1.097 & $1.03-1.17$ & 0.006 & Volume of rectum & 1.028 & $1.00-1.06$ & 0.036 \\
\hline $\begin{array}{l}\text { Percentage of rectum receiving } \\
70 \mathrm{~Gy}\end{array}$ & 1.134 & $1.03-1.25$ & 0.009 & T stage of TNM classification & 4.630 & $1.09-20.00$ & 0.037 \\
\hline $\begin{array}{l}\text { 3DCRT technique } \\
\text { WP vs PO }\end{array}$ & 26.163 & $5.10-134.2$ & 0.000 & $\begin{array}{c}\text { Acute Gl } \\
\text { Low vs High }\end{array}$ & 0.115 & $0.01-0.92$ & 0.042 \\
\hline \multicolumn{5}{|c|}{ Acute GU toxicity } & \multicolumn{3}{|c|}{ Late GU toxicity } \\
\hline Variable & OR & $95 \% \mathrm{Cl}$ & $\mathrm{p}$ & Variable & $\mathrm{OR}$ & $95 \% \mathrm{Cl}$ & $\mathrm{p}$ \\
\hline Age & $1.108^{*}$ & $1.02-1.20$ & 0.015 & Volume of urinary bladder & 1.016 & $1.00-1.03$ & 0.018 \\
\hline $\begin{array}{l}\text { Percentage of urinary bladder receiving } \\
\qquad 50 \mathrm{~Gy}\end{array}$ & 1.127 & $1.01-1.25$ & 0.026 & $\begin{array}{l}\text { Percentage of urinary bladder receiving } \\
\qquad 40 \mathrm{~Gy}\end{array}$ & 1.144 & $1.00-1.30$ & 0.045 \\
\hline \multirow[t]{2}{*}{$\begin{array}{l}\text { Surgical intervention } \\
\text { None vs RP }\end{array}$} & 0.161 & $0.04-0.68$ & 0.013 & $\begin{array}{l}\text { Surgical intervention } \\
\text { None vs RP }\end{array}$ & 0.089 & $0.01-0.85$ & 0.035 \\
\hline & & & & $\begin{array}{l}\text { 3DCRT technique } \\
\text { WP vs PO }\end{array}$ & 0.580 & $0.10-1.74$ & 0.029 \\
\hline
\end{tabular}

Odds ratios (OR), 95\% Confidence Intervals $(\mathrm{Cl})$ and significance levels (p) of Wald chi-square statistic of patient-, tumor-, and treatment-related factors that meet statistical significance are presented 
Table 3 Scoring of GI and GU disorders for WP and PO 3DCRT techniques.

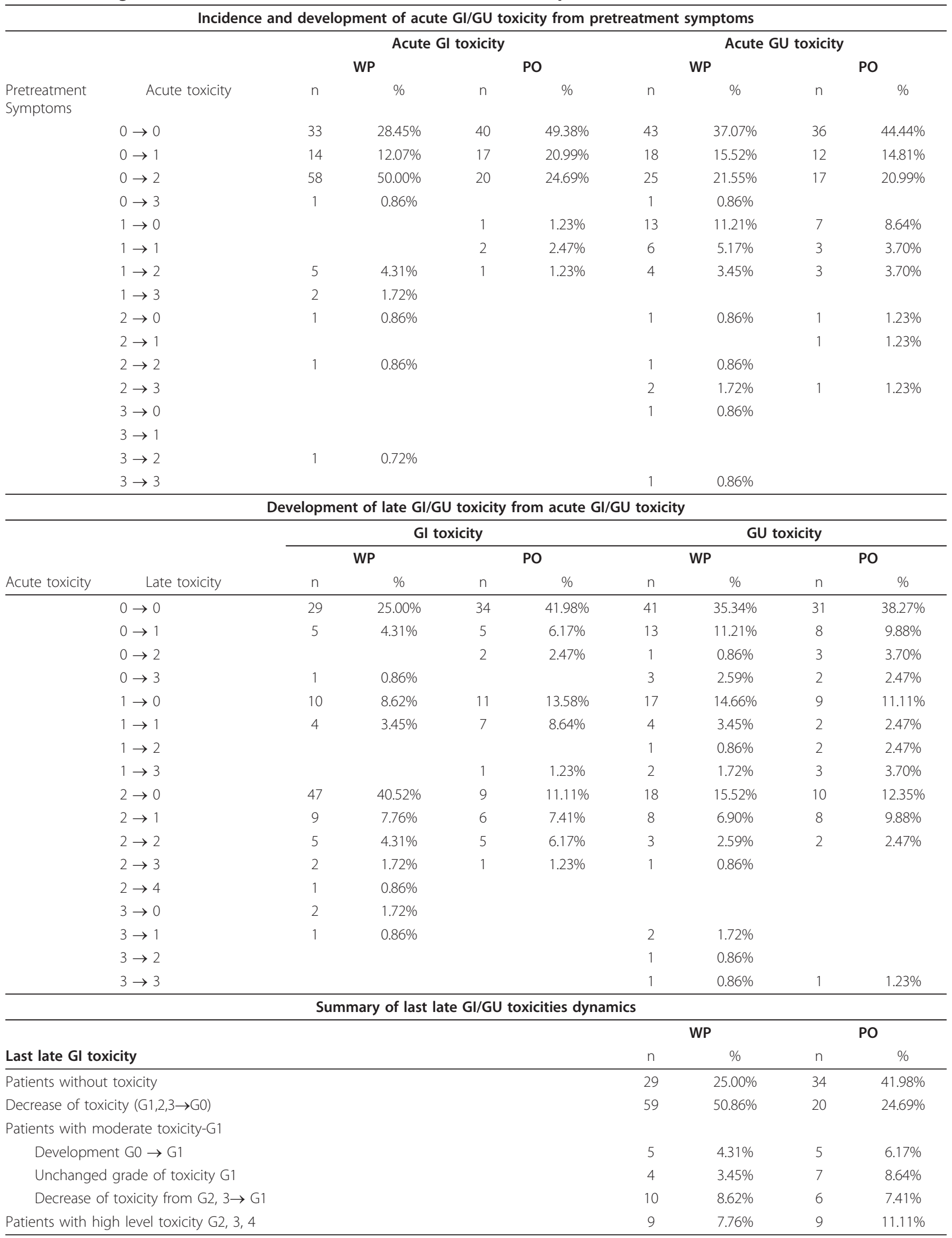


Table 3 Scoring of GI and GU disorders for WP and PO 3DCRT techniques. (Continued)

\begin{tabular}{|c|c|c|c|c|}
\hline \multirow[b]{2}{*}{ Last late GU toxicity } & \multicolumn{2}{|c|}{ WP } & \multicolumn{2}{|c|}{ PO } \\
\hline & $\mathrm{n}$ & $\%$ & $n$ & $\%$ \\
\hline Patients without toxicity & 41 & $35.34 \%$ & 31 & $38.27 \%$ \\
\hline Decrease of toxicity $(\mathrm{G} 1,2,3 \rightarrow \mathrm{G} 0)$ & 35 & $30.17 \%$ & 19 & $23.46 \%$ \\
\hline \multicolumn{5}{|l|}{ Patients with moderate toxicity-G1 } \\
\hline Development G0 $\rightarrow$ G1 & 13 & $11.21 \%$ & 8 & $9.88 \%$ \\
\hline Unchanged grade of toxicity G1 & 4 & $3.45 \%$ & 2 & $2.47 \%$ \\
\hline Decrease of toxicity from $\mathrm{G} 2,3 \rightarrow \mathrm{G} 1$ & 10 & $8.62 \%$ & 8 & $9.88 \%$ \\
\hline Patients with high level toxicity G2, 3, 4 & 13 & $11.21 \%$ & 13 & $16.05 \%$ \\
\hline
\end{tabular}

None of the patients in the PO group suffered grade 2, 3 or 4 pretreatment GI disorders. During RT or within the first 90 days after PO 3DCRT, acute grade 2 GI toxicity occurred in 21 cases $(25.93 \%)$, and there were no patients with grade 3 or 4 GI toxicity. 7 patients (8.64\%) suffered severe late grade 2 GI toxicity, and 1 patient (1.23\%) grade 3. Prior to radiotherapy, 3 patients (3.77\%) had grade 2 toxicity, and none had grade $3 \mathrm{GU}$ toxicity. Acute grade $2 \mathrm{GU}$ toxicity developed in 20 (24.69\%) and grade 3 in $1(1.23 \%)$ patients. Late grade 2 GU toxicity occurred in $7(8.64 \%)$ and grade 3 in 6 (7.41\%) patients. None of the patients in the cohort had grade 4 of GU toxicity. Figure 1 summarizes the proportion of evolution of GI (Figure 1A) and GU (Figure 1B) toxicity events from pretreatment through acute to late damage, for both the WP and PO patient groups. The only disparity between the two 3DCRT techniques was found in the case of development of acute GI toxicity, where a large increase of high level toxicity grades $\geq 2$ was observed in the WP group compared to the PO group. On the other hand, results from Table 3 illustrate the diminution of toxicity from grades $1-3$ to no toxicity (grade 0 ), more prominent in the WP group relative to the PO group. The Pearson's $\chi^{2}$ test was performed to determine the statistical significant difference between the WP and PO 3DCRT techniques, which was observed only in the occurrence of acute GI toxicity ( $p=0.0001)$.

\section{Correlation between the 3DCRT parameters, GI/GU toxicity and immune response}

We screened the immunological parameters, number of leukocytes, distribution of lymphocyte populations (T, B, NK, and NKT cells) and their subsets in the peripheral blood of patients before, throughout and after the finishing of 3DCRT, and correlated them to dose volume parameters, as well as to the volume of irradiated bone marrow.

The relationship of the applied dose and the percentage of volume of bone marrow irradiated are presented in Figure 2. The highest correlation occurred at a dose of $46 \mathrm{~Gy}$, as depicted in Figure 3. We found that the bone marrow irradiation had a significant negative association with the number of leukocytes, but did not influence the proportion of NK cells during the irradiation in doses ranging from 44 Gy to 54 Gy (Table 4). Doses lower than 44 Gy and higher than 54 Gy, did not exhibit statistically significant correlations with leukocyte number. In the scope of PBM irradiation, we found a positive correlation between low doses (1-43Gy) and

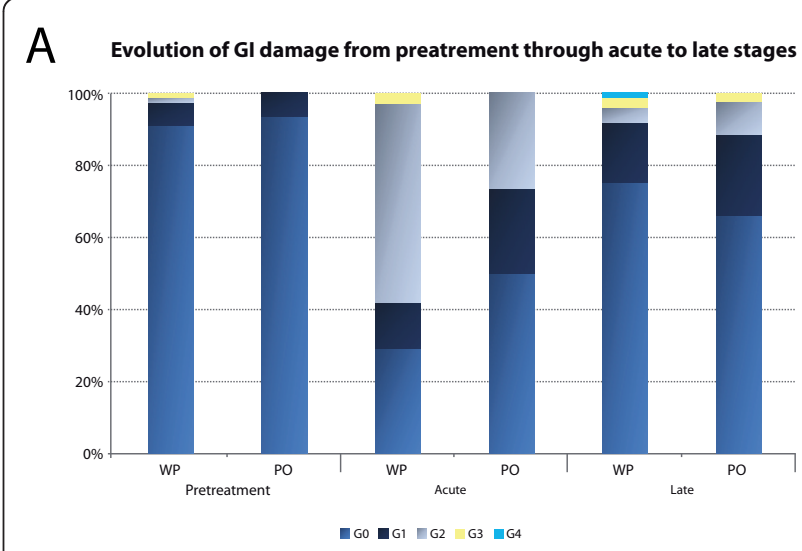

B Evolution of GU damage from pretreatment through acute to late stages

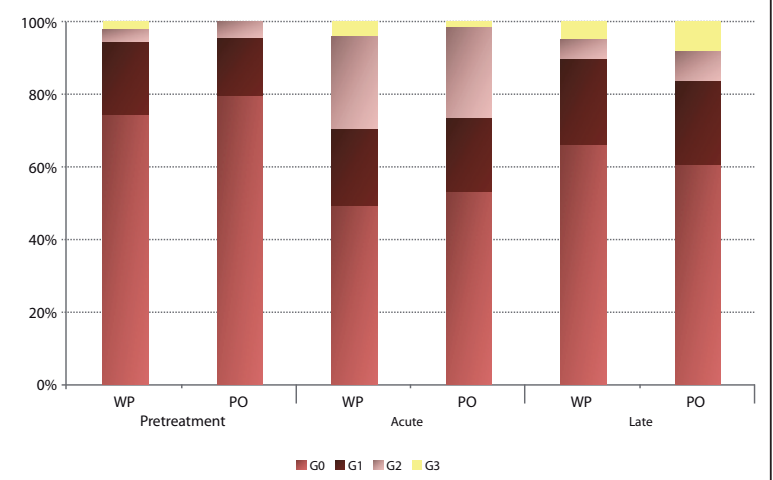

Figure 1 Summary of GI and GU symptoms scoring before and after 3DCRT. Comparison of Gl (A) and GU (B) toxicity between the PO $(n=106)$ and the WP $(n=139)$ patient groups. Patients were scored according to the modification of RTOG morbidity scale. Percentage of occurrence of grades G0, G1, G2, and G3 of pretreatment pathology, acute, and late GU and Gl toxicities are demonstrated. 


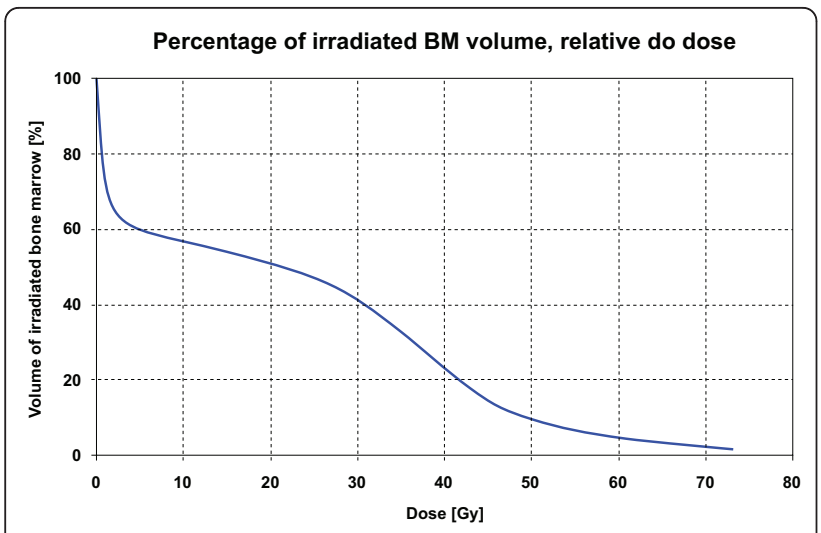

Figure 2 Relationship between the percentage of irradiated volume of bone marrow and the dose applied.

NK cell numbers during RT (Table 4). Blood samples of patients receiving 34-35 Gy to the bone marrow demonstrated significantly increased proportion of NK $(\mathrm{p}=$ $0,002), \operatorname{NKT}(\mathrm{p}=0,005)$ and cytotoxic T cells $(\mathrm{p}=$ 0,018 ) after the end of therapy. Moreover, $T$ lymphocyte proportions in the patient's blood correlated positively with the higher doses (47-62 Gy) of irradiated PBM.

Increased number of resting and terminally differentiated NK cells correlated with several dosimetric parameters, and GI and GU toxicity. Table 5 summarizes the Pearson's correlations between the immune and dosimetric variables on day 14 of RT, and 15-20 days post-radiotherapy. Negative correlation throughout the RT was detected between the NKT cell and T lymphocyte proportion and the volume of the rectum receiving lower and higher doses, respectively. After completion of RT the NK and NKT cells were found to be more sensitive to higher doses. However, positive correlation

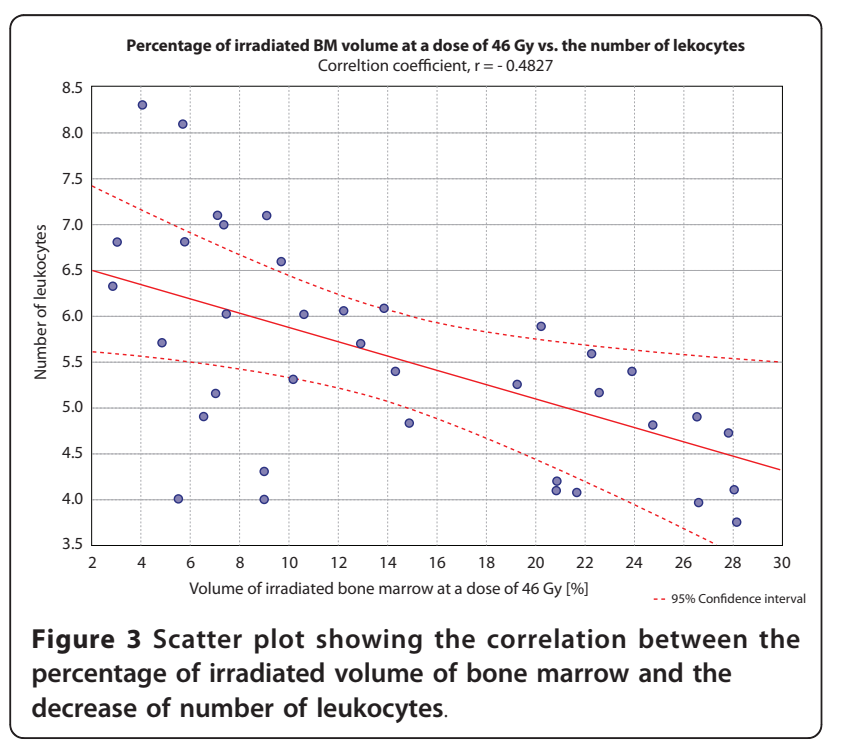

was found between differentiating B lymphocytes, and the irradiated volume of rectum and bladder receiving 70 Gy.

The evaluation of GI and GU toxicity effects in the WP (but not PO) group of patients revealed significant up-regulation of $\mathrm{T}$ lymphocyte numbers $(\mathrm{p}=0.047)$ and NK cell effector function $(\mathrm{p}=0.038)$ during radiotherapy, as well as in patients developing acute GU toxicity. Late GU toxicity-suffering patients had a significantly increased number of CD8+ cytotoxic T cells, $(p=0.002)$ and NK cell killing capability (Table 6). All statistically significant correlation coefficients met the conditions of required sample size. The GI and GU toxicity side effects (after the completion of 3DCRT), but not 3DCRT itself, significantly decreased the distribution of NKT cells in the WP group (Figure 4A). However, the patients treated with the PO 3DCRT, suffering GI and GU toxicities, had a lower number of NKT cells during the entire follow-up (Figure 4B).

\section{Discussion}

In this study two different 3DCRT techniques (WP and PO) were analyzed and the degree of association was determined between the occurrence and evolution of acute and late GI and GU toxicities and the treatment related characteristics in patients entering our hospital. Important findings include: (i) a higher proportion of acute GI toxicity in the WP 3DCRT technique group and conversely a slightly higher proportion of late GI and GU toxicity in the PO patient group; (ii) acute GI toxicity as a significant predictor of late GI toxicity; (iii) a strong dependence of the occurrence and evolution of acute GI toxicity and of late GU toxicity on which 3DCRT technique is used; (iv) the association of both acute and late GU toxicity and radical prostatectomy performed prior to radiotherapy; (v) the influence of age on both acute GI and GU toxicities; (vi) a correlation between the percentage of volume of irradiated bone marrow and a decreased number of leukocytes; and (vii) the influence of radiotherapy preferentially on NK, NKT and $\mathrm{T}$ cell subpopulations.

We found an increase of acute vs. pretreatment GI symptoms predominantly in the WP group, even if the patients were irradiated with lower doses compared with the PO 3DCRT group. We assume that the limiting factor in high-volume irradiation is not the dosimetric parameters, but the overall patient tolerance. In addition, the WP technique was undergone by patients with advanced stages of disease, lower overall health status, and suppressed immune functions. These observations are supported by data of Jereczek-Fossa [19] and Schultheiss et al. [20]; however, some investigators didn't demonstrate this correlation [21]. On the other hand, the diminution of late GI and GU toxicities to 
Table 4 Pearson's correlation coefficients between bone marrow irradiation and immune parameters.

\begin{tabular}{|c|c|c|c|c|c|c|}
\hline \multirow{2}{*}{$\begin{array}{c}\text { Dose } \\
\text { [Gy] }\end{array}$} & \multicolumn{2}{|c|}{ Volume [\%] } & \multicolumn{2}{|c|}{ Number of leukocytes } & \multicolumn{2}{|c|}{ Proportion of NK cells } \\
\hline & Median & Range & Correlation coefficient & $\mathrm{p}$ & Correlation coefficient & $p$ \\
\hline 5 & 44.54 & $30.31-98$ & -0.3177 & 0.140 & 0,5185 & 0,019 \\
\hline 6 & 43.92 & $29.57-98$ & -0.3161 & 0.142 & 0,5197 & 0,019 \\
\hline 7 & 43.38 & $28.95-98$ & -0.3161 & 0.142 & 0,5225 & 0,018 \\
\hline 8 & 42.77 & $28.42-98$ & -0.3162 & 0.142 & 0,5239 & 0,018 \\
\hline 9 & 42.31 & $27.95-97$ & -0.3170 & 0.141 & 0,5236 & 0,018 \\
\hline 10 & 41.86 & $27.53-97$ & -0.3188 & 0.138 & 0,5224 & 0,018 \\
\hline 11 & 41.34 & $27.12-97$ & -0.3213 & 0.135 & 0,5261 & 0,018 \\
\hline 12 & 40.74 & $26.74-96$ & -0.3256 & 0.129 & 0,5196 & 0,019 \\
\hline 13 & 40.13 & $26.36-96$ & -0.3314 & 0.122 & 0,516 & 0,020 \\
\hline 14 & 39.63 & $26.00-96$ & -0.3361 & 0.117 & 0,5147 & 0,020 \\
\hline 15 & 39.13 & $25.66-95$ & -0.3390 & 0.114 & 0,5133 & 0,021 \\
\hline 16 & 38.66 & 25.34-95 & -0.3402 & 0.112 & 0,5124 & 0,021 \\
\hline 17 & 38.20 & $25.03-95$ & -0.3411 & 0.111 & 0,5117 & 0,021 \\
\hline 18 & 37.77 & $24.72-94$ & -0.3423 & 0.110 & 0,5107 & 0,021 \\
\hline 19 & 37.19 & $24.40-94$ & -0.3446 & 0.107 & 0,5096 & 0,022 \\
\hline 20 & 36.35 & 24.05-94 & -0.3463 & 0.105 & 0,5083 & 0,022 \\
\hline 21 & 35.70 & $23.70-93$ & -0.3481 & 0.104 & 0,5065 & 0,023 \\
\hline 22 & 35.20 & 23.33-93 & -0.3496 & 0.102 & 0,5036 & 0,024 \\
\hline 23 & 34.66 & $22.91-92$ & -0.3517 & 0.100 & 0,4984 & 0,025 \\
\hline 24 & 34.13 & 22.37-91 & -0.3675 & 0.084 & 0,4771 & 0,033 \\
\hline 25 & 33.53 & $21.61-83$ & -0.3713 & 0.081 & 0,4579 & 0,042 \\
\hline 44 & $10.97 \dagger$ & $4.38-38.66$ & -0.4619 & 0.027 & 0,4270 & 0,060 \\
\hline 45 & 9.97 & $4.22-35.05$ & -0.4645 & 0.026 & 0,3986 & 0,082 \\
\hline 46 & 9.08 & $4.07-28.04$ & -0.4827 & 0.020 & 0,4153 & 0,069 \\
\hline 47 & 8.39 & $3.93-23.31$ & -0.4769 & 0.021 & 0,3906 & 0,089 \\
\hline 48 & 7.70 & $3.81-21.61$ & -0.4731 & 0.023 & 0,3935 & 0,086 \\
\hline 49 & 7.07 & $3.50-20.48$ & -0.4701 & 0.024 & 0,4023 & 0,079 \\
\hline 50 & 6.54 & $3.15-19.58$ & -0.4710 & 0.023 & 0,4130 & 0,070 \\
\hline 51 & 6.00 & $2.83-18.84$ & -0.4751 & 0.022 & 0,4178 & 0,067 \\
\hline 52 & 5.55 & $2.55-18.16$ & -0.4747 & 0.022 & 0,4187 & 0,066 \\
\hline 53 & 5.21 & $2.30-17.50$ & -0.4709 & 0.023 & 0,4201 & 0,065 \\
\hline 54 & 4.98 & $1.95-16.82$ & -0.4655 & 0.025 & 0,4208 & 0,065 \\
\hline
\end{tabular}

The number of leukocytes and NK cell percentages were correlated to dose received and volume of irradiated bone marrow $(n=37)$

*Required sample size for the obtained correlation coefficients (for $\alpha=0.05$ and power of the test $\beta=0.80$ ) was calculated 32-34 patients

†Statistically significant results are marked in bold

grade 1 or to no toxicity in the majority of acute toxicity (grade 1-3) suffering patients, was observed also in the WP 3DCRT group.

Our data regarding the frequency of severe toxicities are similar to those of other series, despite the fact that a direct comparison of toxicities is difficult due to the existence of many modified versions of the classification, and modifications of grading scales. Similarities were found between our results, the RTOG 9413 [22] analysis, and the GETUG-01 [23] prospective study. The diversity in the diagnostics could be created by individual physicians due to the subjectivity of the scoring system, when the same toxicity could be graded differently. Due to the findings of decreased late GI and GU toxicities after 3DCRT in the cohort of our patients, we compared these results with the studies using hypofractionated stereotactic body radiotherapy SBRT, which is a new modality of localized prostate cancer RT. The SBRT, together with innovations in image-guidance technology, is able to automatically correct the movement of the prostate during treatment, and deliver highly-conformal beam profiles, which have greatly enhanced the capability of delivering high dose fractions to a well-defined target, with sharp dose fall-off towards the bladder and rectum. Most of the studies concerning SBRT as a monotherapy or even as a boost following external beam radiotherapy presented only negligible incidence of severe late GI and GU toxicity. Katz et al. 
Table 5 Pearson's correlation coefficients of immune cells proportions with dosimetric parameters

\begin{tabular}{|c|c|c|c|c|c|c|c|}
\hline \multicolumn{4}{|c|}{$14^{\text {th }}$ date of 3D CRT } & \multicolumn{4}{|c|}{ 15-20 days after completion of 3D CRT } \\
\hline Variable vs. & Variable & $\begin{array}{l}\text { Pearson's } \\
\text { correlation }\end{array}$ & p & Variable vs. & Variable & $\begin{array}{l}\text { Pearson's } \\
\text { correlation }\end{array}$ & $\mathrm{p}$ \\
\hline \multirow[t]{5}{*}{$\begin{array}{c}\text { T cells } \\
(\mathrm{CD} 3+\mathrm{CD} 56-)\end{array}$} & $D_{\min }$ & $-0.5869(20)^{*}$ & 0.012 & $\begin{array}{c}\text { NK cells } \\
\text { (CD3-CD56low) }\end{array}$ & $\begin{array}{l}\text { Percentage of rectum } \\
\text { receiving } 70 \text { Gy }\end{array}$ & $-0.5436(23)$ & 0.024 \\
\hline & $\mathrm{D}_{\text {mean }}$ & $-0.5068(27)$ & 0.032 & & & & \\
\hline & $D_{\max }$ of rectum & $-0.4918(29)$ & 0.038 & & & & \\
\hline & $\mathrm{D}_{\max }$ of urinary bladder & $-0.6089(18)$ & 0.007 & & & & \\
\hline & $\begin{array}{l}\text { Percentage of urinary bladder } \\
\text { receiving } 70 \text { Gy }\end{array}$ & $-0.4906(29)$ & 0.007 & & & & \\
\hline \multirow[t]{4}{*}{$\begin{array}{c}\text { NKT cells } \\
(\mathrm{CD} 3+\mathrm{CD} 56+)\end{array}$} & $D_{\min }$ of rectum & $-0.5776(20)$ & 0.012 & $\begin{array}{c}\text { NKT cells } \\
(\text { CD3+CD56+) }\end{array}$ & $\mathrm{D}_{\max }$ of rectum & $-0.6755(14)$ & 0.000 \\
\hline & $\mathrm{D}_{\text {mean }}$ of rectum & $-0.7243(12)$ & 0.001 & & $\begin{array}{l}\text { Percentage of rectum } \\
\text { receiving } 70 \text { Gy }\end{array}$ & $-0.4148(42)$ & 0.031 \\
\hline & $\begin{array}{l}\text { Percentage of rectum } \\
\text { receiving } 40 \mathrm{~Gy}\end{array}$ & $-0.7363(11)$ & 0.000 & & $\mathrm{D}_{\max }$ of urinary bladder & $-0.6210(17)$ & 0.001 \\
\hline & $\begin{array}{l}\text { Percentage of rectum } \\
\text { receiving } 50 \text { Gy }\end{array}$ & $-0.5613(22)$ & 0.015 & & & & \\
\hline \multirow[t]{4}{*}{$\begin{array}{c}\text { NK cells } \\
\text { (CD3-D56low) }\end{array}$} & $D_{\min }$ of rectum & $0.3963(47)$ & 0.033 & $\begin{array}{c}\text { Activated B cells } \\
\text { (CD19+CD20+ } \\
\text { CD38+) }\end{array}$ & $D_{\min }$ of rectum & $0.4582(34)$ & 0.016 \\
\hline & $D_{\text {mean }}$ of rectum & $0.3724(53)$ & 0.047 & & $\mathrm{D}_{\text {mean }}$ of rectum & $0.4342(38)$ & 0.024 \\
\hline & $\begin{array}{l}\text { Percentage of urinary bladder } \\
\text { receiving } 70 \mathrm{~Gy}\end{array}$ & $0.5152(26)$ & 0.004 & & $\begin{array}{l}\text { Percentage of rectum } \\
\text { receiving } 50 \text { Gy }\end{array}$ & $0.4011(46)$ & 0.038 \\
\hline & & & & & $\begin{array}{l}\text { Percentage of rectum } \\
\text { receiving } 60 \text { Gy }\end{array}$ & $0.5800(20)$ & 0.002 \\
\hline \multirow[t]{4}{*}{$\begin{array}{c}\text { Terminally } \\
\text { differentiated NK } \\
\text { cells } \\
\text { (CD3-CD56+) }\end{array}$} & $\mathrm{D}_{\min }$ & $0.4887(30)$ & 0.040 & $\begin{array}{c}\text { Terminally } \\
\text { differentiated } \\
\text { NK cells } \\
\text { (CD3-CD56+) }\end{array}$ & $\mathrm{D}_{\max }$ of rectum & $-0.5549(22)$ & 0.000 \\
\hline & $\begin{array}{l}\text { Percentage of rectum } \\
\text { receiving } 70 \mathrm{~Gy}\end{array}$ & $0.4835(30)$ & 0.042 & & $D_{\max }$ of urinary bladder & $-0.4608(34)$ & 0.016 \\
\hline & $\begin{array}{l}\text { Percentage of urinary bladder } \\
\text { receiving } 70 \mathrm{~Gy}\end{array}$ & $0.5226(26)$ & 0.026 & & & & \\
\hline & Gl, GU toxicity & $0.5166(26)$ & 0.028 & & & & \\
\hline
\end{tabular}

*Required sample size for correlation coefficient for $\alpha=0.05$ and power of the test $\beta=0.80$ is given in the brackets

Table 6 Influence of GI/GU toxicity on antitumor immune response.

\begin{tabular}{|c|c|c|c|c|c|c|}
\hline Toxicity & Variable & $\begin{array}{c}\text { Mean } \pm \text { SD } \\
\text { (T) }\end{array}$ & $\begin{array}{c}\text { Mean } \pm \text { SD } \\
(0)\end{array}$ & p-value & $\begin{array}{c}N \\
(\mathrm{~T})\end{array}$ & $\begin{array}{l}N \\
(0)\end{array}$ \\
\hline $\begin{array}{l}\text { Acute GU } \\
14^{\text {th }} \text { day } \\
\text { of 3D-CRT }\end{array}$ & $\begin{array}{l}\% \text { of T cells } \\
\text { (CD3+D56-) }\end{array}$ & $68.41 \pm 0.70$ & $58.33 \pm 8.99$ & 0.047 & 26 & $11(6)^{*}$ \\
\hline $\begin{array}{l}\text { Acute GU } \\
14^{\text {th }} \text { day } \\
\text { of 3D-CRT }\end{array}$ & Cytotoxicity & $13.71 \pm 5,21$ & $6.54 \pm 3.12$ & 0.038 & 26 & $11(6)$ \\
\hline $\begin{array}{c}\text { Late GU } \\
15-20 \text { days } \\
\text { after 3D-CRT }\end{array}$ & $\begin{array}{c}\% \text { of } C T L \\
(C D 3+C D 8+)\end{array}$ & $15.99 \pm 6.52$ & $8.55 \pm 2.26$ & 0.002 & 13 & $24(7)$ \\
\hline $\begin{array}{c}\text { Late GI } \\
15-20 \text { days } \\
\text { after } 3 D-C R T\end{array}$ & Cytotoxicity & $25.44 \pm 4.96$ & $13.82 \pm 3.68$ & 0.032 & 14 & $23(2)$ \\
\hline
\end{tabular}

For comparison of immune parameters between the group of patients suffering from any acute and late GU or GI toxicity (T), and the group of patients without toxicity side effects (0) after 3DCRT the t-test was applied.

* Required sample size in each group for given standard deviation and difference of means between groups for $\alpha=0.05$ and power of the test $\beta=0.80$ is given in the brackets 


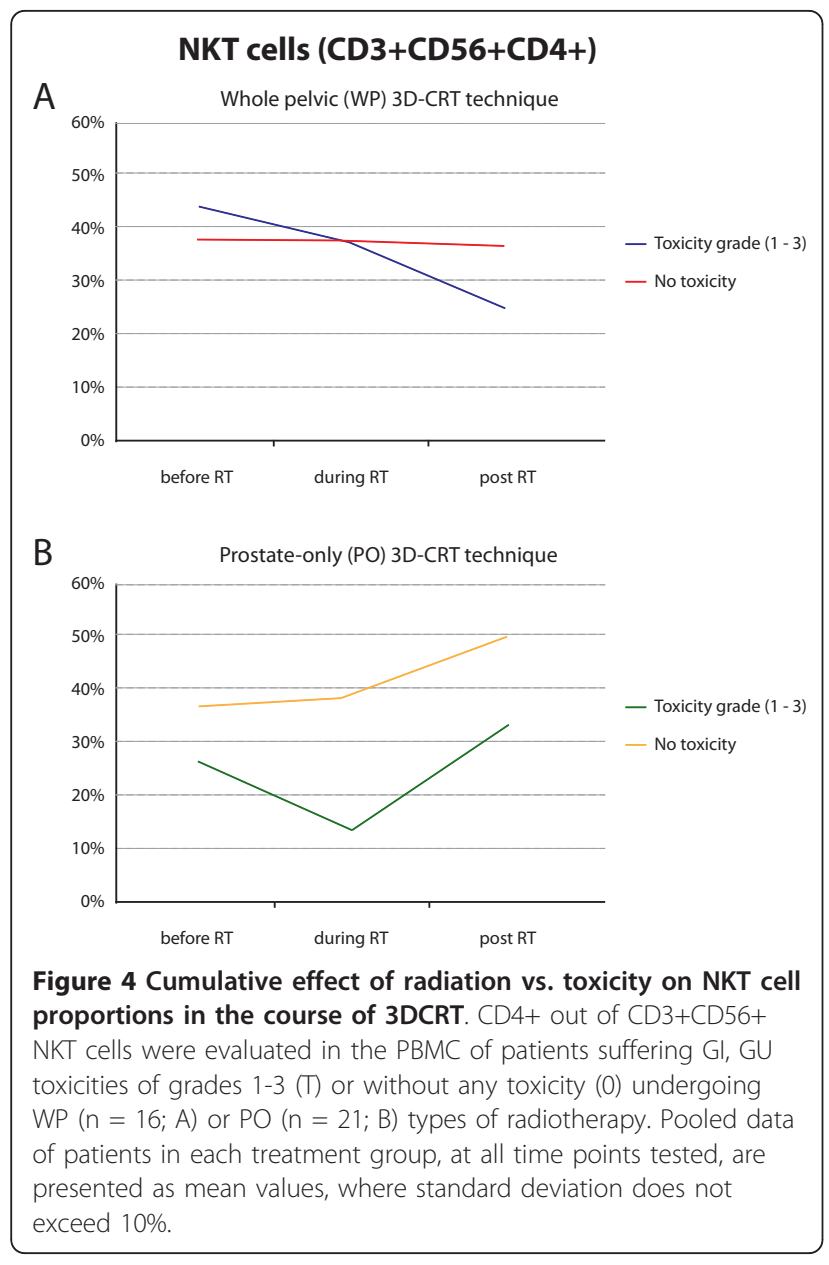

[24,25], Freeman et al. [26] and other authors [27] reported milder toxicity profiles in comparison with our results, particularly in the case of late GI and GU impairments. On the contrary, Jabbari et al. [28] presented in their study similar results as our ones in the occurrence of severe late GU toxicity (grades 2-3), and even worse outcomes in evolution of acute GU toxicity.

The analysis of GU toxicity is difficult, due to interference with pre-existing dysfunction, age-related diseases, and previous urological surgery $[21,29]$. We have to remember that some of these pre-existing symptoms could have been erroneously interpreted as acute or even late GU toxicity. On the other hand, late bladder damage can occur with a long latency time, potentially resulting in the underestimation of the real severity of late toxicity [30]. The difference in the time of clinical manifestation could be the reason why some researchers demonstrated the correlation of acute and late GI, but not GU toxicity [31]. These outcomes were proved in our study, as well.

The development of acute 3DCRT- induced GI and/or GU damage was generally mild in both groups; and none of the patients had an interruption of radiotherapy due to toxicity side effects. The risk of both acute GI and GU reactions depended preferentially on the age of patients, in agreement with the results demonstrated by Jereczek-Fossa et al. [31]. The biological variables and different clinical decisions based on patient age could participate on the final outcome. The association of acute $\mathrm{GU}$ toxicity with the percentage of the urinary bladder receiving 50 Gy found in our study was in accordance with the results of Fiorino et al.[32] and other authors [21,29], who reported a significant correlation between DVH parameters and incontinence. Similarly, the acute GI toxicity associates with the percentage of rectum receiving 70 Gy as demonstrated also by the Italian Association for Radiation Oncology (AIRO) Group on Prostate Cancer (AIROPROS) 0101 trial (previous retrospective investigation [5], who described that the dose of $70 \mathrm{~Gy}$ at rectum was predictive for late G2-G3 bleeding), AIROPROS 0102 [33], and by others $[34,30,7,35]$. Both late GI and GU toxicities positively associated with the volume of the irradiated organ at risk, rectum and urinary bladder, respectively. Furthermore, the late GI toxicity is associated with stage T of TNM classification of the disease, and is strongly influenced by acute GI toxicity. These finding are in agreement with the published data of Heemsbergen et al. [36]. The risk of late GU reactions depended on the percentage of urinary bladder volume receiving $40 \mathrm{~Gy}$, the 3DCRT technique used, and the previous urological surgery $[21,29]$.

Originally, the primary mechanism of RT in cancer reduction has been considered the neoplastic cell DNA damage. However, Takeshima et al. have found that tumor-specific CTL, which were induced in the draining lymph nodes and tumor tissue of mice by RT, are fundamental to the inhibition of cancer growth [37]. The immunological evaluation performed during 3DCRT showed a positive correlation of the number of activated NK cells and the proportion of terminally differentiated tumor targeted cytotoxic effectors with GI and GU toxicities. Both of these subpopulations returned to normal values or decreased after completing $R T$. In contrast, $T$ lymphocytes were decreased during RT and normalized after its completion; while NKT cells were down-regulated in all time periods. The acute GU and late GI and GU toxicities significantly increased the $T$ cell proportion, NK cell-mediated cytotoxicity, and cytotoxic T cell numbers. We assume that these changes are caused by stress conditions induced by RT-damaged and GI or GU toxicity-affected tissues, eliciting stimulation of cytotoxic cells (NK and CTLs). These RT effects could be due to inflammation following increased apoptotic/necrotic events in the involved tissues. The surface expression or extracellular release of stress proteins (e.g. MICs, 
Hsp70), following tumor cell damage by RT, can play a key role in immune system modulation [38]. These molecules are ligands of the NK cell activation receptor NKG2D [39], and can stimulate NK cell functional maturation. Particularly, Hsp72 can act as an immunological adjuvant $[39,40]$, participating in the non-self recognition of prostate cancer cells. Thus we can hypothesize, according to results of Hurwitz et al. [12] that the enhanced immune function, involving resting and terminally differentiated NK cells during 3DCRT, as well as the up-regulation of CTL number and the NK cell-mediated cytotoxicity in GI or GU suffering patients, could follow the release of HSPs either evoked by radiation or by GI or GU toxicity-induced cellular stress.

\section{Conclusion}

Our RT series included 197 patients who were treated in one center and may serve as a basis for comparison with other oncology centers, particularly in the Czech Republic. We found a strong dependence of the development of GI and GU disorders on the 3DCRT technique applied. Most important from a clinical point of view and the overall quality of life of prostate cancer patients after 3DCRT treatment was the diminution of late GI and GU toxicity to grades $0-1$ in a majority of acute toxicities of patients suffering grades 1-3. The relevance of our study lies in the complex evaluation of clinical and radio-therapeutical variables describing the correlations between OARs parameters, GI and GU toxicity, phenotype, and the functional profile of immune cells. Our results brought a new insight into the 3DCRT impact on OARs and the antitumor immune response.

\section{List of abbreviations}

3DCRT: three-dimensional conformal radiotherapy; ADT: androgen deprivation therapy; AUC: area under the curve; BM: bone marrow; CD: cluster of differentiation; CT: computer tomography; CTL: cytotoxic T lymphocyte; CTV: clinical target volume; DVH: dose volume histogram; Gl: gastrointestinal; GU: genitourinary; IBM: iliac bone marrow; ICRU: International Commission on Radiation Units; LENT-SOMA: Late effects in Normal Tissues Subjective, Objective, Management and Analytical scales; LN: lymph nodes; LP: lower pelvis; LS: lumbosacral spine; MLC: multileaf collimator; NK: natural killer; OAR: organs at risk; OR: odds ratio; PBM: pelvic bone marrow; PBMC: peripheral blood mononuclear cells; PO: prostate-only; PSA: prostate-specific antigen; PTV: planning target volume; ROC: receiver operating characteristic; RP/TURP: radical prostatectomy/transurethral resection; RT: radiotherapy; RTOG: Radiation Therapy Oncology Group; WP: whole pelvic.

\section{Acknowledgements}

We thank Drs. Bela Malinova, Anna Kindlova, Jana Prausova, and Michaela Matouskova for excellent cooperation and valuable comments. The work was supported by the Grant agency of the Charles University, GAUK 109908/ 2008 and the Grant agency of the Academy of Sciences of the Czech Republic, IAA500200620.

\section{Author details}

'Department of Medical Biophysics and Medical Informatics, $3^{\text {rd }}$ Faculty of Medicine, Charles University, Prague, Czech Republic. ${ }^{2}$ Department of Radiotherapy and Oncology, Motol University Hospital, Charles University, Prague, Czech Republic. ${ }^{3}$ Department of Immunology and Gnotobiology, Institute of Microbiology, Academy of Sciences of the Czech Republic, v.v.i., Prague, Czech Republic. ${ }^{4}$ Faculty of Biomedical Engineering, Czech Technical University in Prague, Kladno, Czech Republic.

\section{Authors' contributions}

All authors have read and approved the final manuscript. JV, JRo and AF prepared the design of the manuscript; SV made the treatment planning and selected the patients; MS managed the experimental schedule and collected the samples; JRi and AF completed the immunological results; JV created the statistical evaluations; and JV together with $\mathrm{AF}, \mathrm{SV}$, and JRi wrote the paper.

\section{Competing interests}

We have no personal or financial conflicts of interest, and have not entered into any agreement that could interfere with our access to the data on the research, or upon our ability to analyze the data independently, to prepare manuscripts, and to publish them.

Received: 1 April 2011 Accepted: 27 July 2011 Published: 27 July 2011

\section{References}

1. Dale W, Campbell T, Ignacio L, Song P, Kopnick M, Mamo C, Ray P, Vijayakumar S: Self-assessed health-related quality of life in men being treated for prostate cancer with radiotherapy: instrument validation and its relation to patient-assessed bother of symptoms. Urology 1999, 53:359-366.

2. Fiorino C, Sanguineti G, Cozzarini C, Fellin G, Foppiano F, Menegotti L, Piazzolla A, Vavassori V, Valdagni R: Rectal dose-volume constraints in high-dose radiotherapy of localized prostate cancer. Int J Radiat Oncol Biol Phys 2003, 57:953-962.

3. Onal C, Topkan E, Efe E, Yavuz M, Sonmez S, Yavuz A: Comparison of rectal volume definition techniques and their influence on rectal toxicity in patients with prostate cancer treated with 3D conformal radiotherapy: a dose-volume analysis. Radiat Oncol 2009, 4:14.

4. Pinkawa M, Holy R, Piroth MD, Fischedick K, Schaar S, Szekely-Orban D, Eble MJ: Consequential late effects after radiotherapy for prostate cancer-a prospective longitudinal quality of life study. Radiat Oncol 2010, $5: 27$.

5. Rancati T, Fiorino C, Gagliardi G, Cattaneo GM, Sanguineti G, Borca VC Cozzarini C, Fellin G, Foppiano F, Girelli G, Menegotti L, Piazzolla A, Vavassori $V$, Valdagni R: Fitting late rectal bleeding data using different NTCP models: results from an Italian multi-centric study (AIROPROS0101). Radiother Oncol 2004, 73:21-32.

6. Skwarchuk MW, Jackson A, Zelefsky MJ, Venkatraman ES, Cowen DM, Levegrun S, Burman CM, Fuks Z, Leibel SA, Ling CC: Late rectal toxicity after conformal radiotherapy of prostate cancer (I): multivariate analysis and dose-response. Int J Radiat Oncol Biol Phys 2000, 47:103-113.

7. Sohn M, Yan D, Liang J, Meldolesi E, Vargas C, Alber M: Incidence of late rectal bleeding in high-dose conformal radiotherapy of prostate cancer using equivalent uniform dose-based and dose-volume-based normal tissue complication probability models. Int J Radiat Oncol Biol Phys 2007, 67:1066-1073.

8. Liao YP, Wang CC, Schaue D, Iwamoto KS, McBride WH: Local irradiation of murine melanoma affects the development of tumour-specific immunity. Immunology 2009, 128:e797-e804.

9. Bogdandi EN, Balogh A, Felgyinszki N, Szatmari T, Persa E, Hildebrandt G, Safrany G, Lumniczky K: Effects of low-dose radiation on the immune system of mice after total-body irradiation. Radiat Res 2010, 174:480-489.

10. Bordon E, Henriquez-Hernandez LA, Lara PC, Pinar B, Rodriquez-Gallego C, Lloret M: Role of CD4 and CD8 T-lymphocytes, B-lymphocytes and Natural Killer cells in the prediction of radiation-induced late toxicity in cervical cancer patients. Int J Radiat Biol 2010.

11. Tabi Z, Spary LK, Coleman S, Clayton A, Mason MD, Staffurth J: Resistance of CD45RA- T cells to apoptosis and functional impairment, and 
activation of tumor-antigen specific $T$ cells during radiation therapy of prostate cancer. J Immunol 2010, 185:1330-1339.

12. Hurwitz MD, Kaur P, Nagaraja GM, Bausero MA, Manola J, Asea A: Radiation therapy induces circulating serum $\mathrm{Hsp72}$ in patients with prostate cancer. Radiother Oncol 2010, 95:350-358.

13. Liang $Y$, Messer $K$, Rose BS, Lewis JH, Jiang SB, Yashar CM, Mundt AJ, Mell LK: Impact of bone marrow radiation dose on acute hematologic toxicity in cervical cancer: principal component analysis on high dimensional data. Int J Radiat Oncol Biol Phys 2010, 78:912-919.

14. Cannistra SA, Griffin JD: Regulation of the production and function of granulocytes and monocytes. Semin Hematol 1988, 25:173-188.

15. Partin AW, Kattan MW, Subong EN, Walsh PC, Wojno KJ, Oesterling JE, Scardino PT, Pearson JD: Combination of prostate-specific antigen, clinical stage, and Gleason score to predict pathological stage of localized prostate cancer. A multi-institutional update. JAMA 1997, 277:1445-1451.

16. Mell LK, Schomas DA, Salama JK, Devisetty K, Aydogan B, Miller RC, Jani AB, Kindler HL, Mundt AJ, Roeske JC, Chmura SJ: Association between bone marrow dosimetric parameters and acute hematologic toxicity in anal cancer patients treated with concurrent chemotherapy and intensitymodulated radiotherapy. Int J Radiat Oncol Biol Phys 2008, 70:1431-1437.

17. Kuldova M, Svoboda J, Kovaru F, Vannucci L, Kovaru H, Fiserova A: NK cellmediated cytotoxicity modulation by $\mathrm{A}(2)$ adenosine receptor agonist in different mammalian species. Folia Microbiol (Praha) 2009, 54:364-368.

18. Tape TG: The Area Under an ROC Curve [online], University of Nebraska Medical Center. In: Interpreting Diagnostic Tests, Nebraska Medical Center. 2011 [http://darwin.unmc.edu/dxtests/roc3.htm].

19. Jereczek-Fossa BA, Zerini D, Fodor C, Santoro L, Serafini F, Cambria $R$, Vavassori A, Cattani F, Garibaldi C, Gherardi F, Ferrari A, Rocco B, Scardino E, De CO, Orecchia R: Correlation between acute and late toxicity in 973 prostate cancer patients treated with three-dimensional conformal external beam radiotherapy. Int J Radiat Oncol Biol Phys 2010, 78:26-34.

20. Schultheiss TE, Lee WR, Hunt MA, Hanlon AL, Peter RS, Hanks GE: Late GI and GU complications in the treatment of prostate cancer. Int $J$ Radiat Oncol Biol Phys 1997, 37:3-11.

21. Liu M, Pickles T, Berthelet E, Agranovich A, Kwan W, Tyldesley S, McKenzie M, Keyes M, Morris J, Pai H: Urinary incontinence in prostate cancer patients treated with external beam radiotherapy. Radiother Oncol 2005, 74:197-201.

22. A Phase III Trial Comparing Whole Pelvic Irradiation Followed by a Conedown Boost to Boost Irradiation Only and Comparing Neoadjuvant to Adjuvant Total Androgen Suppression (TAS). 2011.

23. Pommier $P$, Chabaud $S$, Lagrange $J L$, Richaud $P$, Lesaunier $F$, Le PE, Wagner JP, Hay MH, Beckendorf V, Suchaud JP, Pabot du Chatelard PM, Bernier V, Voirin N, Perol D, Carrie C: Is there a role for pelvic irradiation in localized prostate adenocarcinoma? Preliminary results of GETUG-01. J Clin Oncol 2007, 25:5366-5373.

24. Katz AJ, Santoro M, Ashley R, Diblasio F, Witten M: Stereotactic body radiotherapy as boost for organ-confined prostate cancer. Technol Cancer Res Treat 2010, 9:575-582

25. Katz AJ, Santoro M, Ashley R, Diblasio F, Witten M: Stereotactic body radiotherapy for organ-confined prostate cancer. BMC Urol 2010, 10:1

26. Freeman $D E$, King CR: Stereotactic body radiotherapy for low-risk prostate cancer: five-year outcomes. Radiat Oncol 2011, 6:3.

27. Fuller DB, Naitoh J, Lee C, Hardy S, Jin H: Virtual HDR CyberKnife treatment for localized prostatic carcinoma: dosimetry comparison with HDR brachytherapy and preliminary clinical observations. Int I Radiat Oncol Biol Phys 2008, 70:1588-1597.

28. Jabbari S, Weinberg VK, Kaprealian T, Hsu IC, Ma L, Chuang C, Descovich M, Shiao S, Shinohara K, Roach M, Gottschalk AR: Stereotactic Body Radiotherapy as Monotherapy or Post-External Beam Radiotherapy Boost for Prostate Cancer: Technique, Early Toxicity, and PSA Response. Int J Radiat Oncol Biol Phys 2010.

29. Sandhu AS, Zelefsky MJ, Lee HJ, Lombardi D, Fuks Z, Leibel SA: Long-term urinary toxicity after 3 -dimensional conformal radiotherapy for prostate cancer in patients with prior history of transurethral resection. Int Radiat Oncol Biol Phys 2000, 48:643-647.

30. Peeters ST, Hoogeman MS, Heemsbergen WD, Hart AA, Koper PC, Lebesque JV: Rectal bleeding, fecal incontinence, and high stool frequency after conformal radiotherapy for prostate cancer: normal tissue complication probability modeling. Int I Radiat Oncol Biol Phys 2006, 66:11-19.
31. Jereczek-Fossa BA, Jassem J, Badzio A: Relationship between acute and late normal tissue injury after postoperative radiotherapy in endometrial cancer. Int I Radiat Oncol Biol Phys 2002, 52:476-482.

32. Fiorino C, Fellin G, Rancati T, Vavassori V, Bianchi C, Borca VC, Girelli G, Mapelli M, Menegotti L, Nava S, Valdagni R: Clinical and dosimetric predictors of late rectal syndrome after 3D-CRT for localized prostate cancer: preliminary results of a multicenter prospective study. Int $J$ Radiat Oncol Biol Phys 2008, 70:1130-1137.

33. Fellin G, Fiorino C, Rancati T, Vavassori V, Baccolini M, Bianchi C, Cagna E, Gabriele P, Mauro F, Menegotti L, Monti AF, Stasi M, Valdagni R: Clinical and dosimetric predictors of late rectal toxicity after conformal radiation for localized prostate cancer: results of a large multicenter observational study. Radiother Oncol 2009, 93:197-202.

34. Fiorino C, Cozzarini C, Vavassori V, Sanguineti G, Bianchi C, Cattaneo GM Foppiano F, Magli A, Piazzolla A: Relationships between DVHs and late rectal bleeding after radiotherapy for prostate cancer: analysis of a large group of patients pooled from three institutions. Radiother Oncol 2002, 64:1-12.

35. Vargas C, Martinez A, Kestin LL, Yan D, Grills I, Brabbins DS, Lockman DM, Liang J, Gustafson GS, Chen PY, Vicini FA, Wong JW: Dose-volume analysis of predictors for chronic rectal toxicity after treatment of prostate cancer with adaptive image-guided radiotherapy. Int I Radiat Oncol Biol Phys 2005, 62:1297-1308.

36. Heemsbergen WD, Peeters ST, Koper PC, Hoogeman MS, Lebesque JV: Acute and late gastrointestinal toxicity after radiotherapy in prostate cancer patients: consequential late damage. Int I Radiat Oncol Biol Phys 2006, 66:3-10.

37. Takeshima T, Chamoto K, Wakita D, Ohkuri T, Togashi Y, Shirato H, Kitamura $H$, Nishimura T: Local radiation therapy inhibits tumor growth through the generation of tumor-specific CTL: its potentiation by combination with Th1 cell therapy. Cancer Res 2010, 70:2697-2706.

38. De Maio A: Extracellular heat shock proteins, cellular export vesicles, and the Stress Observation System: A form of communication during injury, infection, and cell damage: It is never known how far a controversial finding will go! Dedicated to Ferruccio Ritossa. Cell Stress Chaperones 2010.

39. Nausch N, Cerwenka A: NKG2D ligands in tumor immunity. Oncogene 2008, 27:5944-5958.

40. Udono H, Srivastava PK: Comparison of tumor-specific immunogenicities of stress-induced proteins gp96, hsp90, and hsp70. J Immunol 1994 152:5398-5403.

doi:10.1186/1748-717X-6-87

Cite this article as: Vranova et al:: The evolution of rectal and urinary toxicity and immune response in prostate cancer patients treated with two three-dimensional conformal radiotherapy techniques. Radiation Oncology 2011 6:87.

\section{Submit your next manuscript to BioMed Central and take full advantage of:}

- Convenient online submission

- Thorough peer review

- No space constraints or color figure charges

- Immediate publication on acceptance

- Inclusion in PubMed, CAS, Scopus and Google Scholar

- Research which is freely available for redistribution

Submit your manuscript at www.biomedcentral.com/submit
C Biomed Central 